\title{
MOLÉSTIA DE CHAGAS CRÔNICA ASSOCIADA A LEUCEMIA LINFÁTICA: OCORRÊNCIA DE ENCEFALITE AGUDA COMO ALTERAÇÃO DO ESTADO IMUNITÁRIO
}

\author{
L. C. Mattosinho França * \\ R. NEgRÃo Fleury ** \\ H. ARANTES RAMos JR. ****
}

\author{
SÉRgIo DE LEMOS ** \\ R. Melaragno Filho*** \\ JACYR PASTERNAK *****
}

O comprometimento do sistema nervoso central na forma aguda da doença de Chagas foi descrito pelo descobridor da moléstia em $1911^{7}$. Em sua sistematização clínica, Chagas dividiu as formas agudas em benignas e graves, estas tendo alterações nervosas, ocorrendo predominantemente nos primeiros anos de vida, e com decurso fatal ${ }^{8}$. Os estudos anátomo-patológicos dos casos iniciais de Carlos Chagas foram feitos por Gaspar Vianna ${ }^{22}$, o qual caracterizou morfològicamente a meningo-encefalite. Magarinos Torres ${ }^{14}$, em 1923, definiu a encéfalo-mielite chagásica como processo benigno de curso agudo, com localização multifocal nas substâncias cinzenta e branca. Relatos ulteriores de Bertrand ${ }^{4}$ e de Talice e col. ${ }^{21}$, dão ênfase ao caráter agudo da encefalite e à sua ocorrência no decurso da fase aguda da doença de Chagas.

Alterações neurológicas na forma crônica da moléstia de Chagas foram inicialmente referidas em 1923 por Villela ${ }^{23,24}$, que as considerou como decorrentes de cicatrização de meningo-encefalite. Austregésilo, em 1927, reviu os aspectos clínico-neurológicos da moléstia de Chagas, salientando a existência da forma crônica ${ }^{2}$. Borges Fortes, em 1942, separou as alterações do sistema nervoso central em agudas e crônicas, sendo estas caracterizadas por seqüelas de encefalite, com gliose e rarefação celular ${ }^{3}$.

Outras alterações nervosas aparecem na doença de Chagas. Fenômenos embólicos cerebrais, a partir de tromboses cardíacas, foram descritos por Nussenzweig e col. ${ }^{15}$ em 1953. Comprometimento do sistema nervoso periférico foi descrito por Couceiro ${ }^{9}$, em 1953. As alterações do sistema nervoso autônomo foram extensamente descritas por Köberle ${ }^{11}$ e por Okumura e col. ${ }^{16}$.

Os estudos experimentais da doença de Chagas sempre confirmaram os achados clínicos de ser a meningo-encefalite fenômeno da fase aguda da doença, segundo os achados de Magarinos Torres ${ }^{13}$; Villela e Magarinos Torres ${ }^{25,26}$ e Souza Campos ${ }^{20}$.

Trabalho do Hospital do Servidor Público Estadual de São Paulo: * Chefe, Anatomia Patológica; ** Assistentes, Anatomia Patológica; *** Chefe, Neurologia; $* * * *$ Assistente, Neurologia; $* * * *$ Assistente, Hematologia Clínica. 
A existência de fatôres de agravamento da moléstia de Chagas foi inicialmente referida por Mazza em $1936^{12}$, ulteriormente por Jaffe em $1954{ }^{10}$ e por Yaeger em $1960^{28}$, entendendo êsses autores que hipovitaminoses várias levam ao agravamento da evolução da forma aguda experimental da doença.

Pizzi, em $1961^{18}$, estudando a imunologia da doença referia ser a intensidade das alterações mórbidas secundária a fatôres do hospedeiro e do parasita. Os fatôres do hospedeiro incluem imunidade natural, raça de uma dada espécie, idade e sexo, estado nutricional e fatôres de reação inicial (fagocitose). Os fatôres do parasita incluem cêpa, virulência, histiotropismo, dose e via de inoculação. A imunidade adquirida da doença é caracterizada por destruição dos parasitas ao nível dos tecidos, tendo grande importância a fagocitose. As formas sangüícolas não são afetadas. A função dos anticorpos não é bem conhecida, e recém-nascidos com títulos altos podem apresentar formas agudas. A imunidade é alterada por irradiação total sub-letal, por bloqueio do SRE por dióxido do tório coloidal, e pela cortisona nos estágios iniciais da doença ${ }^{18}$.

No presente trabalho é relatado o caso de paciente com forma crônica da moléstia de Chagas, no qual instalou-se encefalite chagásica aguda; leucemia linfática constituiu o fator de agravamento da forma crônica da moléstia de Chagas.

\section{O B S E V A C A O}

Q.L. (registro 43.091), 65 anos de idade, masculino, côr preta, natural de Descalvado, Estado de São Paulo. Procurou o Hospital pela primeira vez em agôsto de 1963, em estado de insuficiência cardíaca, com edema periférico, dispnéia, pressão arterial de $210 \times 105 \mathrm{~mm} \mathrm{Hg}$, pulso 48 . Recebeu tratamento sintomático, e abandonou o tratamento antes da alta ambulatorial. Em fevereiro de 1967 procurou novamente o Hospital, com história de vômitos e diarréia há uma semana, e perda da fôrça nos membros inferiores. Estava desidratado, pulso 104, pressão arterial de $160 \times 120 \mathrm{~mm} \mathrm{Hg}$, temperatura de $38^{\circ} \mathrm{C}$. Extrassistoles isoladas. Fígado palpável a um dedo do rebôrdo costal, doloroso. Baço percutível. o exame neurológico mostrou ređução da fôrça muscular nos membros inferiores, abolição dos reflexos profundos, sensibilidade conservada e midriase bilateral, mais intensa à esquerda. Hemograma: 40.000 leucócitos por $\mathrm{mm}^{3}$, com $50 \%$ de linfocitos. Mielograma: leucemia linfática crônica. Exame de líquido céfalorraquidiano: punção lombar; aspecto límpido e incolor; pressão inicial 15 (manômetro Claude); 6 células por $\mathrm{mm}^{3}$ (100\% de linfocitos); proteínas $20 \mathrm{mg} / 100 \mathrm{ml}$; cloretos $696 \mathrm{mg} / 100 \mathrm{ml}$; glicose $100 \mathrm{mg} / 100 \mathrm{ml}$; reações de Takata-Ara, Wasserman, VDRL, Steinfeld e Weinberg negativas. Eletrencefalograma: atividade elétrica discretamente lenta, sem anormalidade localizada. O paciente permaneceu internado por 68 dias, tendo picos febris diários entre 38 e $39,2^{\circ} \mathrm{C}$. A partir do $26 .^{\circ}$ dia ficou sonolento, tendo aparecido afasia no $300^{\circ}$ dia, e ficando inconsciente a partir de 49.0 dia. Esteve com sonda vesical de demora durante tôda a internação, havendo hematúria persistente. Nos últimos dias houve instalação de edema generalizado. O óbito deu-se por parada respiratória. O tratamento constou de quimioterápicos, antibióticos, analgésicos, diuréticos, corticóides, vitaminas, sôro glicosado, cuidados gerais e dietéticos. Não foram feitas transfusões de sangue.

O exame necroscópico (Autópsia A67-114) demonstrou a presença de condições mórbidas múltiplas, representadas por leucemia linfática crônica, moléstia de Chagas, arteriosclerose generalizada, adenocarcinoma do sigmóide, broncopneumo- 
nia, hiperplasia nodular da próstata e bócio colóide nodular. A leucemia linfática foi caracterizada pela presença de infiltrado leucêmico nos gânglios linfáticos, baço, fígado, suprarrenais, músculos e nervos periféricos. A arteriosclerose foi caracterizada por acometimento da aorta, coronárias, vasos cerebrais e renais, predominantemente. O adenocarcinoma do sigmóide era restrito à parede intestinal, não havendo metástases. A broncopneumonia era bastante extensa e bilateral. A moléstia de Chagas foi caracterizada pela presença de miocardite crônica, com demonstração de ninhos de leishmanias em fibras cardiacas. Havia intensa fibrose intersticial do coração, e hipertrofia de fibras. Infiltrado intersticial mononuclear estava presente. Meningo-encefalite aguda chagásica foi demonstrada, caracterizada por infiltrado celular mononuclear na leptomeninge $e$ ao redor dos vasos do parênquima, e grande número de granulomas microgliais disseminados em todo o encéfalo. No interior de alguns dêsses granulomas, e no interior de células de tipo astrocítico, foram observados ninhos de leishmanias. Não foram observadas alterações na medula espinhal.

\section{COMENTARIOS}

A doença de Chagas apresentada pelo paciente era de tipo crônico, dada a existência de cardiomegalia global, fibrose intersticial do miocárdio, hipertrofia de fibras e reação inflamatória crônica focal. Já a meningo-encefalite tinha os caracteres observados na fase aguda da moléstia, segundo o relato na literatura ${ }^{14}$, havendo numerosos ninhos de leishmanias em meio ao parênquima nervoso. Não tendo o paciente recebido transfusões sangüíneas que explicassem os aspectos agudos da doença por super-infecção exógena, deve o caso ser interpretado como forma de reativação endógena da doença de Chagas.

A existência de leucemia linfática crônica concomitante fornece elementos para a interpretação da reativação da doença de Chagas neste paciente, com instalação de encefalite aguda.O aparecimento de infecções agudas na evolução de casos relativos a doentes com leucemia e com linfomas é de conhecimento geral, e amplamente relatado na literatura médica ${ }^{1}$. A imunologia moderna aceita ser a produção de anticorpos própria aos linfocitos e plasmocitos. A produção de anticorpos, seja segundo a interpretação da teoria instrutiva (Paulding-Burnet-Fenner ${ }^{17,5}$ ), seja segundo a teoria de seção clonal (Burnet ${ }^{6}$ ), tem como fenômeno básico a existência de linhagem linfocitária específica para a produção de cada anticorpo. Na vigência de leucemia linfática, com substituição progressiva dos linfocitos típicos por linhagens de linfocitos atípicos, um ou mais clones linfocitários podem desaparecer, deixando assim de existir a base celular para a produção de um ou mais anticorpos específicos, dependentes das linhagens que desapareceram. Nesses têrmos, a existência da leucemia linfática no caso presente pode ter levado à extinção das linhagens linfocitárias responsáveis pela imunidade adquirida à moléstia de Chagas, criando, assim, condições para a agudização do processo e instalação de encefalite aguda. 


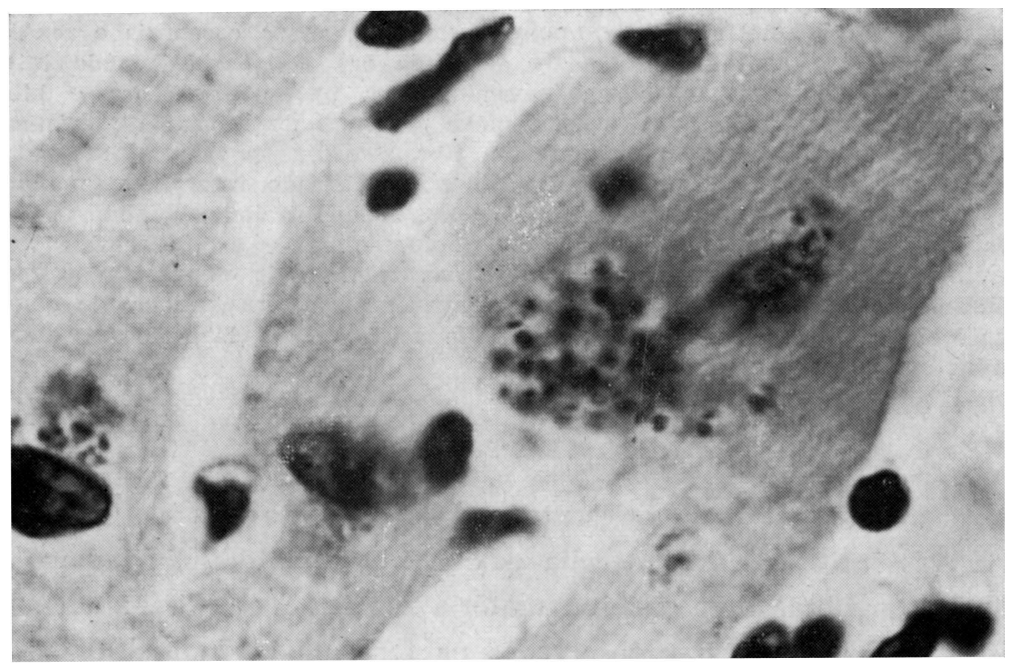

Fig. 1 - Caso Q.L. Coração, $1215 \times$, coloração H.E. Ninhos de leishmanias ern fibras miocárdicas. Notar presenca de blefaroplastos.

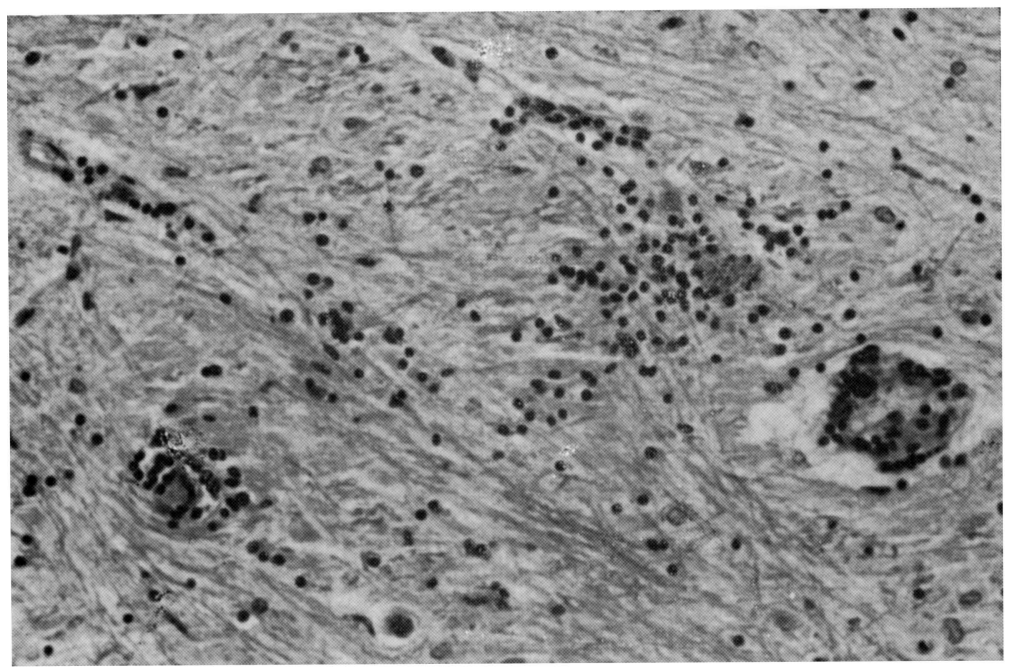

Fig. 2 - Caso Q.L. Cérebro, $195 \times$, coloração H.E. Infiltrado mononuclear perivascular, focos de proliferação microglial. 


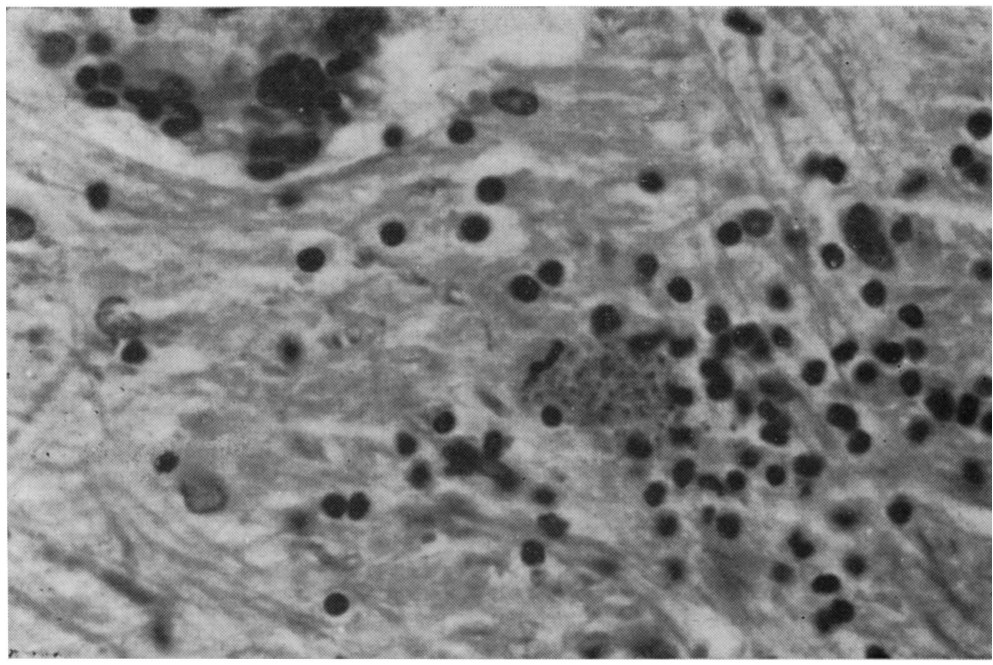

Fig. 3 - Caso Q.L. Cérebro, $485 \times$, coloração H.E. Nódulo microglial circundando conglomerado de leishmanias.

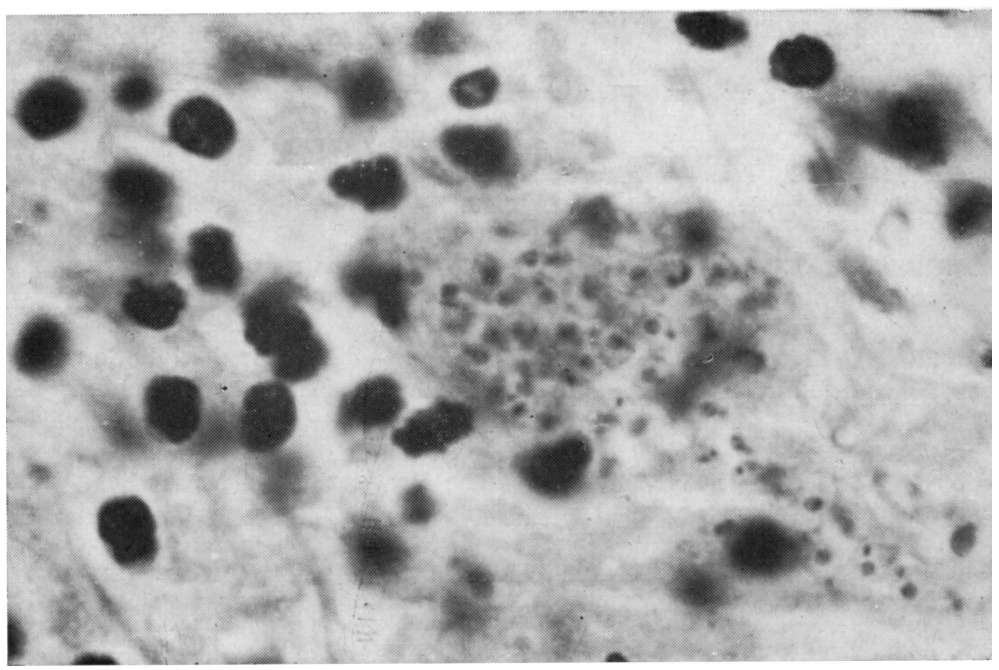

Fig. 4-Caso Q.L. Cérebro, $1215 \times$, coloração H.E. Nódulo microglial circundando agrupamento de leishmanias. Notar presenca de blefaroplastos. 
É relatado um caso de paciente apresentando a forma crônica da doença de Chagas, no qual foi observada a presença de encefalite chagásica aguda, com demonstração de leishmanias no sistema nervoso central. $O$ caso é único na literatura, sendo interpretado como devido a agravamento da forma crônica da doença de Chagas pela presença de leucemia linfática crônica associada. A existência de leucemia linfática pode levar à extinção de clones linfocitários responsáveis por fenômenos imunitários, criando, assim, condições para o agravamento e agudização da forma crônica da doença de Chagas.

\section{S U M M A R Y}

Chronic Chagas disease associated with lymphatic leukemia: occurrence of acute encephalitis as a possible alteration of the immune state.

A case of chronic Chagas disease, associated with chronic lymphocitic leukemia is reported. Acute manifestations of Chagas disease, characterized by acute encephalitis, with demonstration of Leishmaniae in the central nervous system were observed. This aspect is unique in the literature, since Chagas encephalitis appears only as a manifestation of the acute form of the disease, and not as a complication of the chronic form. The fact is interpreted, in this case, as secondary to alteration of the immune state, due to the presence of chronic lymphocitic leukemia.

RE FER E N I A S

1. ANDERson, W. A. R. - Pathology. C. V. Mosby Co., St. Louis, 5th Edition, 1966.

2. AUSTREgESILO, A. - Alterações nervosas em certas enfermidades tropicais. Rev. neurol. (Paris) 1:21, 1927.

3. BORGES-FORTES, A. - As lesões do sistema nervoso na enfermidade de Chagas. Jornal dos Clínicos 23:355-361, 1942.

4. BERTRAND, I.; BABLET, J. \& SICÊ, A. - Lésions histologiques des centres nerveux dans la trypanosomiase humaine. Ann. Inst. Pasteur 64:91-147, 1935.

5. BURNET, F. M. \& FENNER, F. - The Production of Antibodies. MacMillan \& Co. Ltd., Melbourne, 1948.

6. BURNET, F. M. - The clonal selection theory of acquired immunity. University Press, Cambridge, 1959.

7. CHAGAS, C. - Nova entidade mórbida do homem. Resumo geral de estudos etiológicos e clínicos. Mem. Inst. Oswaldo Cruz 3:219-275, 1911.

8. CHAGAS, C. - Tripanosomíase americana. Forma aguda da moléstia. Mem. Inst. Oswaldo Cruz 8:37-63, 1916. 
9. CouCEIRo, A. - Lesões do ciático na infecção experimental do cão pelo Schizotrypanum cruzi. Mem. Inst. Oswaldo Cruz 39:435-439, 1953.

10. JAFFE, R.; GAVALER, B. \& DOMINGUEZ, A. - Importancia del factor hipovitaminosis $B_{1}$ em la miocarditis alergica experimental. Arch. Venezol. Patol. Trop. y Parasitol. med. 2:183-187, 1954.

11. KOBERLE, F. - Patogenia da moléstia de Chagas. Rev. goiana Med. 3: 155-180, 1957.

12. MAZZA, S. \& JORG, M. E. - Infeccion natural mortal por S. cruzi en cachorro de perro pila de Jujuy. Novena Reunión Soc. argentina Patol. reg. 365-411, 1936.

13. MAGARINOS-TORRES, C. \& VILLAÇA, J. - Encefalite e mielite causadas por um tripanosomo (T. cruzi). Mem. Inst. Oswaldo Cruz 11:80-88, 1919.

14. MAGARINOS-TORES, C. - A tripanosomose americana e a sua anatomia patológica.Folha med. 4:25-29, 1923.

15. NUSSENZWEIG, I.; SPINA-FRANÇA, A.; WAJCHEMBERG, B. L.; TTMONER, J.; MACRUZ, R. \& SERRO-AZUL, L. G. - Acidentes vasculares cerebrais embólicos na cardiopatia chagásica crônica. Arq. Neuro-Psiquiat. (São Paulo) 11:386-402, 1953.

16. OKUMURA, M.; MATTOSINHO-FRANÇA, L. C. \& CORREA-NETTO, A. Comentários sôbre a patogenia da moléstia de Chagas, com especial referência à infecção experimental em camundongos. Rev. Hosp. Clín. Fac. Med. São Paulo 18:151-164, 1963.

17. PAULDING, L. - Theory of structure and process of formation of antibodies. J. Am. Chem. Soc. 62:2643-2650, 1940.

18. PIZZI, T. - Imunologia de la enfermedad de Chagas: estado actual del problema. Bol. Ofic. Sanit. Panam. 450-464, 1961.

19. SOUZA-CAMPOS, E. - Estudos sôbre a raça neurotrópica do Trypanosoma cruzi. An. Fac. Med. São Paulo 2:197-201, 1927.

20. SOUZA-CAMPOS, E. - Paralisia experimental determinada pelo Trypanosoma cruzi de origem humana. Bol. biológico 2:153-173, 1927.

21. TALICE, R.; COSTA, R. S.; RIAL, B. \& OSIMANI, J. J. - Los 100 primeros casos agudos confirmados de enfermedad de Chagas en el Uruguay. Monteverde \& Cia., Montevideo, 1940.

22. VIANNA, G. - Contribuição para o estudo da anatomia patóógica da moléstia de Chagas. Mem. Inst. Oswaldo Cruz 3:276-294, 1911.

23. VILLELA, E. - A transmissão intrauterina da moléstia de Chagas. Encefalite congênita pelo T. cruzi. Folha med. 4:41, 1923.

24. Villela, E. - Moléstia de Chagas: forma nervosa. Folha med. 4:49-52, 1923.

25. VILLELA, E. \& MAGARINOS-TORRES, C. - Estudo histopatológico do sistema nervoso central em paralisia experimental determinada pelo S. cruzi. Mem. Inst. Oswaldo Cruz 19:175-198, 1926. 
66 ARQ. NEURO-PSIQUIAT. (SÄO PAULO) VOL. 27, N.० 1, MARCO, 1969

26. VILLELA, E. \& MAGARINOS-TORRES, C. - Lésions histo-pathologiques dans la paralysie expérimentale a Schisotrypanum cruzi chez le chien. Nature des cellules contenant le parasite dans le système nerveux central. C. R. Soc. Biol. 93:133-135, 1925.

27. Villela, E. \& Villela, C. - Elementos do sistema nervoso central parasitados pelo T. cruzi. Mem. Inst. Oswaldo Cruz 26:77-82, 1932.

28. YAEGER, R. G. \& MILLER, O. N. - Effect of malnutrition on susceptibility of rats to Trypanosoma cruzi: thiamine defficiency. Experimental Parasisitol. 9:215-222, 1960.

Hospital do Servidor Público Estadual de São Paulo - Rua Pedro de Toledo, 1.800 - São Paulo, SP - Brasil. 